\title{
An Empirical Study on Productive Vocabulary Acquisition Under Hypertext Reading
}

\author{
https://doi.org/10.3991/ijet.v13i12.8846 \\ Hui Li $\left.{ }^{(}\right)$, Gengsheng Xiao \\ University of South China, Hengyang, China
}

873123889 @qq. com

\begin{abstract}
This research aims to examine the effect of hypertext reading on productive vocabulary acquisition, and investigate how other influential factors mainly including students' English proficiency and their use of vocabulary learning strategies affect the outcome of productive vocabulary acquisition. Both quantitative and qualitative research methods are adopted in this study. A test and a questionnaire survey were conducted. Two parallel classes of English major, who are all sophomores, are randomly selected as the control group and the experimental group respectively. According to the results of analysis, some conclusions are drawn. First, though participants can acquire productive vocabulary both in traditional reading and hypertext reading, hypertext reading is more effective. Second, the effectiveness of hypertext reading in productive vocabulary acquisition is more significant for learners of extremely high/low English proficiency than those of intermediate level. Third, vocabulary learning strategies that are employed influence the effect of hypertext reading on productive vocabulary acquisition.
\end{abstract}

Keywords - productive vocabulary acquisition; traditional reading; hypertext reading

\section{$1 \quad$ Introduction}

Compared with the features of traditional reading, which is static, hypertext reading is characterized with non-linear text, interactivity and multimedia. However, while most researchers still focus on traditional reading, research on hypertext reading is limited. Until the $20^{\text {th }}$ century, with the development of technology, people nowadays widely use computer and network in their work and life. Thus, an increasing number of researchers turn their interest from traditional reading to hypertext reading. They mainly do research on the features of hypertext, problems in hypertext reading and readers' reading behaviors, etc. Hypertext reading, which is a new style of reading, has made great difference to the way of reading.

Undoubtedly, hypertext reading may also influence second/foreign language teaching, for it has played an important role in language education. It is the contemporary technology that not only presents in English class, but also introduces the research on productive vocabulary acquisition in a new way. But if someone wants to know how to 
make full use of hypertext reading in class, the first and foremost thing is to compare the distinction of traditional reading and hypertext reading. Only in this way can we know which method is more effective and what the advantages and disadvantages are. Though many researchers turn their attention to the differences in some pedagogical effects between traditional reading and hypertext reading, they ignore how differently productive vocabulary is acquired in traditional reading and hypertext reading. Therefore, this research intends to discuss the differences between traditional reading and hypertext reading in productive vocabulary acquisition.

\section{$2 \quad$ Literature Review}

Since the 1970 s, vocabulary acquisition has gradually become a hot research topic in the field of second language acquisition. Lewis [1] maintained that vocabulary acquisition was the central task of second language acquisition, and it was such a lifelong cognitive process that nobody could master the total number of words of a language.

Also, many researchers turn their attention to the productive vocabulary acquisition. Some researchers abroad examine the breadth and depth of second language productive vocabulary acquisition. Some scholars explore the measure of the total amount of words of L2 learners. Hulstijn Hollander and Greidanus [2] investigated the influence of marginal glosses, dictionary use and reoccurrence of unknown words on incidental vocabulary acquisition, and the result showed that the mastery of new words acquired by dictionary use is better than those by marginal glosses. Another experiment from Hulstijn has shown that passages with multiple marginal glosses are more conductive to the memory of words acquired incidentally the ones with annotations, but he also found that learners were likely to choose the wrong answer in multiple marginal glosses.

Meanwhile, researchers also explore the relevant study between the relationship of learners' size of vocabulary and vocabulary acquisition capability. Thus the researchers focus more on the depth of second language vocabulary acquisition. However, many researchers at home also concentrate on productive acquisition based on the different theories. Zhao [3] studied the acquisition of productive vocabulary for non-English majors, which was based on the lexical chunk. She concluded that the vocabulary acquisition which was based on the lexical chunk could do great help to productive vocabulary acquisition. Few years later, Lie [4] also studied on the productive vocabulary acquisition, which was based on memetics. He drew the same conclusion as Lie Xiaojing, and he suggested that memetics could be applied in second language teaching. Besides the studies on productive vocabulary acquisition, a few researchers gradually notice that reading is one of the best ways to acquire vocabulary. Thus, in recent years, some researchers have studied the productive vocabulary acquisition from the aspects of some classic theories to their ways of learning vocabularies. Zhao [5] researched incidental productive vocabulary acquisition in reading, which was based on the involvement load hypothesis. Just like the study that Zhao Lili conducts, most of the studies on productive vocabulary are through reading on printed paper, but a few studies focus on the acquisition in hypertext reading. While with the wide use of computer, hypertext reading 
may take a very important place in the future teaching. Consequently, this study mainly focuses on the comparison between traditional reading and hypertext reading in productive vocabulary acquisition. The following questions will be answered:

1.Is hypertext reading more effective in productive vocabulary acquisition, than traditional reading?

2. What is the relationship between learners' English proficiency and their acquisition of productive vocabulary under hypertext reading?

3. What is the relationship between learners' use of vocabulary learning strategies in the hypertext reading and their acquisition of productive vocabulary?

\section{$3 \quad$ Productive Vocabulary and Hypertext Reading}

There are two obviously contrastive phrases that need to be clarified: productive and receptive, traditional text reading and hypertext reading. Thus, all the terms will be explained respectively.

\subsection{Productive Vocabulary Acquisition}

In this part, the definition of productive vocabulary, the relationship between productive vocabulary and receptive vocabulary and the definition of productive vocabulary acquisition will be described in details.

Productive Vocabulary. Richard [6] is known as the first person to mention that there are seven aspects of knowing vocabulary knowledge. According to Richard, if one intends to acquire a word, he should acquire its frequency prediction and association of its synonyms, appropriateness of use, syntactic functions or grammatical features, basic form and derisive forms, inter-word association, conceptual meaning as well as polysemy [7].

Based on the Richard's research, Nation [8] got some ideas. He defined the vocabulary knowledge as receptive vocabulary and productive vocabulary. And the vocabulary framework which was put forward by Nation was showed in the Table 1.

From Table 1, we can see that the process of knowing a word involves eight types of word knowledge. They are spoken form, written form, grammatical patterns, collocation, frequency, appropriateness, concept and association. In the table, $\mathrm{R}$ stands for receptive knowledge, while $\mathrm{P}$ stands for productive knowledge. From the perspective of productive knowledge and receptive knowledge, Nation studies all the eight types of vocabulary knowledge. Receptive vocabulary refers to the vocabulary that can be understood and recognized in listening or reading context, while productive vocabulary refers to the vocabulary that can not only be understood or recognized but also could be used appropriately in speaking or written context [8].

Laufer [9] divided vocabulary knowledge into passive (receptive), controlled active (productive) and free active. The passive word is the word whose most frequent meaning can be understood. Controlled active word is the word that one can recall by giving some cues. And free active knowledge stands for spontaneous use of the word in a context generated by the user, which is designed in response to a writing assignment. 
Table 1. Knowing a Word

\begin{tabular}{|c|c|c|}
\hline \multicolumn{3}{|r|}{ Form } \\
\hline \multirow{2}{*}{ Spoken form } & $\mathbf{R}$ & What does the word sound like? \\
\hline & $\mathbf{P}$ & How does the word pronounce? \\
\hline \multirow{2}{*}{ Written form } & $\mathrm{R}$ & What does the word look like? \\
\hline & $\mathrm{P}$ & How is the word written and spelt? \\
\hline \multicolumn{3}{|r|}{ Position } \\
\hline \multirow{2}{*}{ Grammatical patterns } & $\mathrm{R}$ & In what patterns does the word occu \\
\hline & $\mathrm{P}$ & In What patterns must we use the word? \\
\hline \multirow[t]{2}{*}{ Collocation } & $\mathrm{R}$ & $\begin{array}{l}\text { What words or types of words can be expected before or after the } \\
\text { word? }\end{array}$ \\
\hline & $\mathrm{P}$ & What words or types of words must we use with the word? \\
\hline \multicolumn{3}{|r|}{ Function } \\
\hline \multirow{2}{*}{ Frequency } & $\mathrm{R}$ & How common is the word? \\
\hline & $\mathrm{P}$ & How often should the word be used? \\
\hline \multirow{2}{*}{ Appropriateness } & $\mathrm{R}$ & Where would we expect to meet word? \\
\hline & $\mathrm{P}$ & Where can this word be used? \\
\hline \multicolumn{3}{|r|}{ Meaning } \\
\hline \multirow{2}{*}{ Concept } & $\mathrm{R}$ & What does the word mean? \\
\hline & $\mathrm{P}$ & What word should be used to express this meaning? \\
\hline \multirow{2}{*}{ Association } & $\mathrm{R}$ & What other words does this word makes us think of? \\
\hline & $\mathrm{P}$ & What other words could we use instead of this one? \\
\hline
\end{tabular}

$\mathrm{R}=$ Receptive vocabulary $\mathrm{P}=$ Productive vocabulary

It can be concluded that receptive vocabulary and productive vocabulary are the different aspects of knowing the knowledge of a word. Furthermore, though there are various definitions about productive vocabulary, productive vocabulary in this study means the word that learners can spell and use to translate the sentences correctly.

Relationship Between Productive Vocabulary and Receptive Vocabulary. Meara, who distinguished the receptive vocabulary and productive vocabulary, held the view that passive items "can only be accessed if appropriate external stimulation is available, while productive vocabulary does not require any external stimulus but can be activated by other words" [10]. From Meara's description, receptive vocabulary and productive vocabulary are totally different.

Nation [8] stated that productive knowledge of a word included receptive knowledge. It also extends the receptive knowledge of a word. In other word, if a word is regarded as one's productive vocabulary, one is able to comprehend and recognize it in reading or listening context. Meanwhile, the vocabulary should be spelt and pronounced correctly. Learners shouldn't only use the vocabulary with low frequency. One also needs to use the vocabulary in an appropriate context. Furthermore, one should use other words to express the meaning it represents. Finally, if a substitute is needed for this word, one is able to find another word to replace it. From Nation's expression, it is easy to see that productive vocabulary is the extension of receptive vocabulary.

However, some other researchers state that there is a gap between receptive vocabulary and productive vocabulary, but the gap is not very large and it varies according 
to some semantic or pragmatic factors. Laufer [9] conducted a study on the relationship among three types of English vocabulary knowledge--passive (receptive), controlled active (productive) and free active. He drew a conclusion that an increase in one's passive vocabulary would result in the increase in one's controlled active vocabulary, but it may also widen the gap between them, because when one's passive word is low, he will try to use the high frequent words but avoid using some low frequent words. But in other occasion, with the extension of one's passive words, less frequency words he will use and learn. The bigger the passive word size is, the more frequent the number of words that may not enter the active axis.

Definition of Productive Vocabulary Acquisition. Productive vocabulary acquisition, which is regarded as one part of the second language vocabulary acquisition, should be introduced after the term second language vocabulary acquisition.

Second Language Vocabulary Acquisition, which is an important part of the Second Language Acquisition, involves some other disciplines, such as, Linguistics, Psychology, Education, etc. , "Second Language Acquisition" refers to the conscious or subconscious process by which the language other than the mother tongue is learnt in a natural or tutored way" [11].

Unlike Second Language Acquisition, there is no authorized and universally recognized definition about Second Language Vocabulary Acquisition. Channel defined it as follows: "I regard a Second Language word as having been acquired by a learner when (a) its meaning can be recognized and understood rather than guessed at both in and out of context, and (b) it can be used naturally and appropriately in situation" [12].

In this study, if the learner knows the specific meaning of the vocabulary and can use it in a proper way in real context, and a conclusion can be drawn that the learner will acquire the vocabulary. Second language vocabulary acquisition in this study will definitely mean the English vocabulary acquisition in Chinese context [13].

\subsection{Hypertext Reading}

Hypertext is another important terminology in the research of this paper. Its definition and main features will be introduced as follows. Meanwhile, it's very necessary to distinguish the traditional text reading and hypertext reading, so that the study on the productive vocabulary acquisition in traditional reading and hypertext reading can go on more smoothly and clearly. Thus, the distinction between traditional reading and hypertext reading will be discussed as follows.

Definition of Hypertext. In 1945, the term "hypertext" was first proposed by Vannevar Bush. And Ted Nelson coined hypertext in 1963. Then, in 1965, he proposed it in a report of the Association of Computing Machinery. Ted Nelson defined "hypertext" as "a combination of natural language text with the computer's capacity for interactive branching, or dynamic display...of a non-linear text...which cannot be printed conveniently on a conventional page" [14]. Another authoritative definition about hypertext is from the Shorter Oxford English Dictionary, which describes hypertext as "a body of text...stored in machine readable form and structured in such a way that a reader can cross-refer between related items of information." 
From the perspective of Bellamy [15], hypertext was in a position of linking all the scattered units, such as, words, sentences, paragraphs or segments of the picture/sound/text by computer's linking system. Thus, learners could obtain a larger number of information by this way and hypertext was known as hypermedia. "Since the end of the twentieth century, with the appearance of the Hyper Text Transfer Protocol (HTTP) and Hyper Text Mark-up Language (HTML) and the establishment of World Wide Web (WWW), hypertext has taken the dominant role in the field of electronic publications" [16].

Meanwhile, in order to read hypertext more efficiently, Barnes [17] proposed that learners should master at least three skills: computer operating skills, traditional reading skills and hypertext reading skills. Hypertext is usually regarded as the electronic forms of text. Therefore, if learners would like to read hypertext efficiently, they must master some basic knowledge and traditional reading skills. In the age of information and Internet, computer plays the major role in our daily life. Most people are required to operate the computer well, in case that the difficulty of hypertext reading will be increased, so grasping some computing skills is another concern for reading hypertext. At last, some hypertext reading skills is very necessary, such as: mastering the knowledge of the document's structure, employing a multiphase approach to reading and the operation of obtaining more information by hyperlinks.

What's more, hypertext can be easily distinguished from traditional text, because hypertext possesses its own unique features. Thus, the main features of hypertext will be introduced in the following part.

Main Features of Hypertext. Traditional reading refers to reading texts or passages that are printed on the paper. With the appearance of the modern information technology, people's way of reading has been changed from traditional reading to hypertext reading. Traditional reading is faced with a great challenge, because hypertext reading can provide more information and bring convenience to readers by the hyperlinks which are set by the designers in advance. Hypertext reading is regarded as a unique way of reading. Thus, its main features will be introduced as follows.

Non-linearity. Traditional reading text is characterized with linear order, closed and static text. The sequence of the text is designed in advance, and readers can only read the text in succession. However, hypertext reading is nonlinear, open and dynamic [18]. It has no fixed sequence, but the hypertext designers will set some hyperlinks in advance, so readers are allowed to obtain more background information or related information. Meanwhile, they can also read the text by clinking the computer mouse, and then enter a three or four-dimensional space.

Interactivity. With the rapid development of technology and Internet, the appearance of hypermedia has made great difference to hypertext. It also provides more opportunities for readers to enhance the interactivity. Hypermedia has adopted a great number of man machine interfaces, so readers can select the materials in accordance with their knowledge level and language competence. They may also choose the language contents that they are interested in [19]. For making the interactivity between hypertext and readers more convenient, it's necessary for the hypertext designers to provide more space and opportunities for readers to select. 
Moreover, photo-illustrated text, audio-visual text, such as, videos, music, photos, and descriptive sentences are applied in hypertext and hypermedia, so readers can obtain various kinds of materials. It can also broaden readers' horizon by providing all types of related knowledge. Meanwhile, readers are given more autonomy to select their own reading material and arrange their own schedules [20].

Multimedia. As mentioned above, hypertext reading is nonlinear, open and dynamic. It presents various materials by using hyperlinks. The information content that hypertext links can be multimedia; the node of hypertext can be various media forms. From what is shown above, it's easy to draw the conclusion that multimedia is indispensable in hypertext reading.

In conclusion, hypertext is characterized with nonlinearity, interactivity and multimedia. These three features distinguish the hypertext reading from traditional text reading. The distinction between them will be discussed as follows.

The Distinction Between Hypertext Reading and Traditional Reading. Hypertext reading refers to reading the text that is shown on the computer screen, while traditional reading refers to reading the text that is printed on paper. When it comes to the distinction between hypertext reading and traditional reading, their main features should be discussed at first. The main features of traditional text reading are linear, close and static. On the contrary, hypertext reading is nonlinear, open and dynamic. On the other hand, hypertext is in the electronic form. Thus, hypertext reading also has close relationship with the traditional reading. Therefore, in order to read hypertext more efficiently, mastering some basic traditional reading skills is very important.

\section{$4 \quad$ Research Methodology}

This part will introduce the participants, reading material and instrument in details.

\subsection{Participants}

The experiment is made in University of South China. The total number of participants is 47, who are selected from two parallel classes. All of them are sophomores of English major. One class of 21 participants is the control group, who read the text that is printed on paper. The other class of 26 participants is the experimental group, who read the hypertext.

\subsection{Materials}

In this part, it introduces how the author determines the reading material and target words in it.

Reading Materials. When it comes to the reading material, the difficulty level of reading material is beyond readers' English level but the main idea can still be understood or inferred. The reading material of this paper is chosen from one of the TEM-8 reading articles, named The Most Important of All Human Qualities is a Sense of Humor. The total number of vocabulary is 512 . A pilot study was conducted to decide 
whether this passage is appropriate for the participants. A parallel class was selected, from which the twenty-six students were required to read this passage and then judge the difficulty level of this passage. From the research, most of the students held the view that the difficulty level of this passage is appropriate. Though there are some new words, they maintain these won't influence their understanding. Thus, author eventually takes this passage as the reading material for testing. Choosing the proper reading material is the key factor to determine the success of study. What's more, the procedure of deciding target words cannot be ignored, because it will influence the validity of the study to some extent.

Target Words. To decide the target words is the second important step. As shown above, a parallel class participated in the preliminary study. They not only judged the difficulty level of this passage, but also pointed out the words that are new to them. After it has been finished, author collects all the materials and selects 20 target words that are new to the participants. Whether the participants can acquire these 20 target words in traditional reading and hypertext reading is the first important thing. And the experimental group can use the hyperlinks that the author sets in advance. The content of the hyperlinks is about other web pages that are related to target words, for example: relevant news, pictures, videos, music, or some detailed description on them. Author designs the hyperlinks on all target words separately. After author sets hyperlinks, the target words or chunks will be underlined. During the period of reading, if the participant moves the computer mouse to the target word, a shape of hand will be showed. Then if he clicks the mouse, it will turn into another web page which obtains some relevant materials. In order to let the participants be in a natural condition, they are not told that target words are set some hyperlinks. Meanwhile, they are not required to use the hyperlinks and expand their reading by these.

\subsection{Instruments}

In order to conduct this study successfully, the author makes use of two kinds of instruments: test and questionnaire, which are designed for different purposes. Purpose of test is to know well whether productive vocabulary can be acquired in traditional reading and hypertext reading, and which way is more effective in acquiring productive vocabulary. However, the questionnaire plays the role of complement; that is to say, the questionnaire is in charge of the matters that the test can't deal with. The questionnaire is designed to study how other factors affect the outcome of productive vocabulary acquisition. Thus, the detailed description of test and questionnaire will be clarified as follows.

All the participants are required to finish the translation exercises that are relevant to the target words. There are 20 exercises in total, each exercise is one score, and thus, the total score is 20 . The result of the participants' vocabulary acquisition is based on the score that participants get. A questionnaire is attached behind the test paper, which includes (1) participants' personal information: name, students' number (2) participants' grade of major courses (3) new word strategy: looking up the new words with printed dictionary or electronic dictionary, using mobile phones or other translation 
machines, inducing from context; employing some vocabulary strategies, as word-formation strategies and asking teachers or classmates for help. (4) participants' reading behaviors: the sequence of reading and doing exercises (5) how they use the hyperlinks, and whether it's useful.

\subsection{Procedure}

Research procedure is the most important step in the whole study, which will decide whether this research is valid or not. Thus, the author conducts two kinds of studies: the pilot study and the main study.

The pilot study is also called preliminary study, which is the indispensable part in the process of research. In pilot study, the reading material, target words, hyperlinks, test and questionnaire are designed for the preparation of the formal study.

The formal study is conducted in two parallel classes. One is control group, who read the passage on the printed paper. The other is experimental group, who read the passage on the computer screen. All the participants are required to finish the translation exercises and questionnaire immediately after they read the passage. And they are not told to take the test but do the seat-work or homework that are assigned by their English teacher, because only in this way can all the participants be in a natural condition and the research can be regarded as valid. For the controlled group, they will be assigned to finish their reading, translation exercises and questionnaire during the period of class, while the experimental group is given the Uniform Resource Locator link, so the participants should search into the site and read the passage with their phones or computers. All of them can use printed or electronic dictionaries to look up the new words when they are reading the passage, but they are not allowed to search the new words when they are doing the translation exercises. Most importantly, they must finish the test on their own. Therefore, it's very necessary for the teacher to supervise students during the period of doing the exercises.

\section{$5 \quad$ Results and Discussion}

After participants finish the whole translation exercises and questionnaire, the author collects all the materials. Then the author analyzes the data in order to answer four questions that have been mentioned in the literature review. The result will be shown in tables. Finally, the author will put forward some constructive suggestions for the English teachers' vocabulary teaching in reading. And in the following parts, the result and data analysis of the test and of the questionnaire will be discussed respectively.

\subsection{Effectiveness of Hypertext Reading in Productive Vocabulary Acquisition}

The test contains several sections. The most important part is the analysis of the marks obtained from the translation exercises. Therefore, the scores of both experimental group and control group are required to be analyzed respectively in detail to see 
whether productive vocabulary can be acquired by two groups and whether there are any distinctions between them.

Though it has been mentioned that experimental group and control group are chosen from two parallel classes, the equivalence still needs to be presented and emphasized. Thus, the basic information of two groups and the result of the test will be shown in Table 2 and Table 3.

Table 2. The Basic Information of CG and EG

\begin{tabular}{|l|l|c|c|c|c|}
\hline \multicolumn{1}{|c|}{ Group } & \multicolumn{1}{|c|}{ Reading way } & Total number & Male & Female & Average score \\
\hline CG & Traditional Text Reading & 21 & 2 & 19 & 81.92 \\
\hline EG & Hypertext Reading & 26 & 2 & 24 & 80.26 \\
\hline
\end{tabular}

Note: $\mathrm{CG}=$ Control Group $\mathrm{EG}=$ Experimental Group

As has been shown in the table 2, it can be concluded that the experimental group and the control group are very equivalent in terms of gender distribution and English proficiency. After translation test was taken among them, then the result will be analyzed as follows in the Table 3.

Table 3. Result of the Translation Test

\begin{tabular}{|l|l|c|}
\hline \multicolumn{1}{|c|}{ Group } & \multicolumn{1}{|c|}{ Reading way } & Result of the translation test (Mean score) \\
\hline CG & Traditional Text Reading & 9.15 \\
\hline EG & Hypertext Reading & 12.72 \\
\hline
\end{tabular}

From table 3, we can see the mean score of control group and experimental group are 9.15 and 12.72 respectively. Thus, a conclusion can be drawn that participants can acquire more productive vocabulary in hypertext reading than traditional reading. Likewise, Zhang [21] drew the same conclusion that hypertext has a better reading effect than traditional printed text in the web-based environment. Therefore, hypertext reading is more effective than traditional reading for facilitating learners' acquisition of productive vocabulary.

However, whether students with higher levels of English proficiency can better acquire productive vocabulary still remains unknown. Therefore, the result will be displayed in the Table 4.

\subsection{Relationship Between English Proficiency and Productive Vocabulary Acquisition Under Hypertext Reading}

There are many factors that may influence students' acquisition of productive vocabulary under hypertext reading, among which the learners' English proficiency is especially crucial. In the following table, whether the English level is positively correlated with the test score will be discussed.

As can be seen from the Table 4, result of the participants of intermediate English level in control group has no significant difference with those in experimental group. 
Table 4. Result of Learners in Different English Level

\begin{tabular}{|l|c|c|c|c|}
\hline Group & $\mathbf{7 0} \leq \mathbf{X}<\mathbf{7 5}$ & $\mathbf{7 5} \leq \mathbf{X}<\mathbf{8 0}$ & $\mathbf{8 0} \leq \mathbf{X}<\mathbf{8 5}$ & $\mathbf{8 5} \leq \mathbf{X}<\mathbf{9 0}$ \\
\hline CG & 7 & 7 & 10 & 12.6 \\
\hline EG & 11.25 & 8.86 & 12.8 & 18 \\
\hline
\end{tabular}

But for those of low English level and high English level, especially the latter, the way of hypertext reading is more effective than that of traditional text reading. There is no doubt that all participants can acquire productive vocabulary no matter in traditional reading or in hypertext reading. However, hypertext reading is especially compatible with excellent students of high English proficiency, who can acquire productive vocabulary far more effectively than their counterparts reading in a traditional way. Hypertext reading also well fits those students of low English proficiency, for this reading mode greatly enhances productive vocabulary acquisition. Anyway, the effectiveness of hypertext reading is not significant for those of intermediate English proficiency.

Though half of questions are answered, there are still some other factors that may influence the result. Hence it will be discussed in the analysis of the questionnaire.

\subsection{Relationship Between Vocabulary Learning Strategy Use and Productive Vocabulary Acquisition Under Hypertext Reading}

Owing to different ways of reading, two kinds of questionnaires are designed. Both of them involve questions about participants' reading behaviors and new word techniques for the sake of knowing whether they will exert impact on the result of productive vocabulary acquisition. Meanwhile, the questionnaire that is designed for control group, adds some other questions to test how participants think of the hyperlinks and whether it is useful for them or not. At the beginning, the common questions for experimental group and control group will be presented in the Table 4 and 5.

Table 5. Number of New Words

\begin{tabular}{|l|c|c|c|c|c|}
\hline \multicolumn{7}{|c|}{ Number of New words } \\
\hline Group & Very Large & Large & Neither small nor large & Small & Very small \\
\hline CG & 1 & 3 & 10 & 7 & 0 \\
\hline EG & 1 & 14 & 11 & 0 & 0 \\
\hline Total & 2 & 17 & 22 & 7 & 0 \\
\hline
\end{tabular}

Table 6. The Difficulty Level of Reading Material

\begin{tabular}{|l|c|c|c|c|c|}
\hline \multirow{2}{*}{ Group } & \multicolumn{5}{|c|}{ Difficulty level } \\
\cline { 2 - 6 } & Very difficult & Difficult & Neither easy nor difficult & Easy & Very easy \\
\hline CG & 1 & 2 & 17 & 1 & 0 \\
\hline EG & 0 & 10 & 16 & 0 & 0 \\
\hline Total & 1 & 12 & 33 & 1 & 0 \\
\hline
\end{tabular}


From Table 5 and Table 6 , we can see $70 \%$ of participants maintain that the difficulty level of this passage is appropriate. On the other hand, there are almost $86 \%$ of them who hold the view that enough new words were involved in this passage. In other word, all participants may not have difficulty in understanding this passage even though some new words exist. However, when author conducts this test, some situations can't be avoided, so author has to show these in the questionnaire. According to the result, every participant finishes the test on their own, and they do translation exercises after reading the whole passage within 20 minutes. Therefore, we can make sure this study is valid and the result can be regarded as conceivable. Finally, another important factor that may affect participant's result of productive vocabulary acquisition is their vocabulary learning strategy. Consequently, the difference of vocabulary learning strategies in two different reading models should be discussed in details.

For the sake of knowing how participants use vocabulary learning strategies, author analyzed the open-ended question in the questionnaire---what kind of vocabulary learning strategies do you use when you are encountered with new words?. From their answer, we know that participants in the control group and experimental group use different strategies. First, for the participants in the experimental group, almost $74 \%$ of them said that they usually use e-dictionary or online dictionary when they encounter with new words. They maintain that e-dictionary is so convenient that they can not only know the literal meaning of the word but also know more related information about it, such as model sentences, news reports, etc., which can show them the real context to use it. Moreover, the participants of high English level are more likely to use e-dictionary. Surely, they use more than one strategies when dealing with new words. Second, for those in the control group, most of them use printed dictionary, because they think it's authoritative and it contains comprehensive information. However, it also has disadvantages. Once those participants look up new words in the printed dictionary, they will be stuck in the plenty of information, which makes it hard for them to figure out the key information. Third, those who use e-dictionary or online dictionary as a vocabulary learning strategy have on thing in common: high grade in the translation test.

From the above results, we can know that participants in the experimental group use e-dictionary commonly, while those in the control group use the printed dictionary more often. Those of high English level are more likely to use e-dictionary or online dictionary, and they thus achieve productive vocabulary acquisition more effectively than other strategy users.

\section{Conclusion}

By employing both quantitative and qualitative research methods, the present study empirically investigates productive vocabulary acquisition under hypertext reading, and the following research findings have been obtained. First, it can be concluded that no matter which way of reading is used, participants can acquire productive vocabulary. But participants who finish their reading on the computer screen and make use of hyperlinks may do better in acquiring vocabulary than those who read the passage in the printed paper. Second, the effectiveness of hypertext reading in productive vocabulary 
acquisition is more significant for learners of extremely high/low English proficiency than those of intermediate level. Third, from the perspective of understanding the meaning of new words, participants may employ different kinds strategies to learn new words. These vocabulary learning strategies influence the outcome of productive vocabulary acquisition to some extent.

Thus, second language teachers should attach greater importance to introducing hypertext reading to their students and guide them to know more about hyperlinks in daily teaching, and moreover, teachers are suggested to give students' vocabulary learning strategy training under hypertext reading to effectively promote their acquisition of productive vocabulary.

Meanwhile, there are still some limitations in this study which need to be pointed out. First, the number of participants both in the experimental group and the control group is relatively small and in future research a larger sample is expected. Second, in this study only translation test is employed to measure productive vocabulary acquisition and in future research writing test and/or speaking test can be added. Finally, the present research just explored the influence of two factors on productive vocabulary acquisition, namely, English proficiency and vocabulary learning strategy and therefore, and therefore, more influential factors are expected to be studied in further research.

\section{$7 \quad$ Acknowledgment}

This work was supported by the Ministry of Education in China's Project of Humanities and Social Sciences (No.15YJC740106), the National University Foreign Language Teaching and Research Project (No. 2014HN0018A), and the Research Project of Teaching Reform in Higher Education in Hunan Province (No. 2017/229).

\section{References}

[1] Lewis, M. (1996). Pedagogical Implications of the Lexical Approach. In Coady, J. e Huckin T. (a cura di), Second Language Vocabulary Acquisition. Cambridge: Cam-bridge University Press, 255-270. https://doi.org/10.1017/CBO9781139524643.018

[2] Hulstijn, J. H. (1992). Retention of inferred and given word meanings: Experiments in incidental vocabulary learning. Vocabulary and Applied Linguistics, 113-125. https://doi.org/10.1007/978-1-349-12396-4_11

[3] Zhao, X. (2001). Acquisition of Productive Vocabulary for Non-English Majors-A Study Based on Lexical Chunk. Yanan University.

[4] Lie, X. (2013). A Study of Productive Vocabulary Acquisition in College English Based on Memetics. Shangdong Normal University.

[5] Zhao, Li. (2011). A Study on Incidental Productive Vocabulary Acquisition in Read-ing Based on the Involvement Load Hypothesis. Shenyang Normal University.

[6] Richard, J. C. (2001). The Context of Language Teaching. Beijing: Foreign Language Teaching and Research Press. 
Paper-An Empirical Study on Productive Vocabulary Acquisition Under Hypertext Reading

[7] Liu, S. (2003). On acquisition and development of second language: Developmental difference hypothesis of vocabulary knowledge based on empirical investigation. Foreign Language Education, 24 (6) :47-50.

[8] Nation, I. S. P. (1990). Teaching and Learning Vocabulary. Rowley, MA: Newbury House.

[9] Laufer, B. (1998). The development of passive and active vocabulary in a second lan-guage: Same or different. Applied Linguistics, 19 (2): 255-271. https://doi.org/10.1093/applin/19.2.255

[10] Meara, P. (1990). A note on passive vocabulary. Second Language Research, 6 (2): 150154.

[11] Ellis, R. (1999). Understanding Second Language Acquisition. Shanghai: Shanghai Foreign Language Education Press.

[12] Channel, J. (1998). Psycholinguistic consideration in the study of L2 vocabulary ac-quisition[J]. Vocabulary and Language Teaching, 83-96.

[13] Feng, Y. (2011). An Empirical Research of Incidental Vocabulary Acquisition through College English Reading. Shenyang Normal University.

[14] Nelson, T. A. (1965). File Structure for the Complex, the Changing and the Indetermi-nate. In Proceedings of the ACM 20th National Conference. New York: ACM Press.

[15] Bellamy, C. (2002). The Web, Hypertext, and History: A Critical Introduction-Research Portal. London: King's College.

[16] Zhu, Z. (2011). Research on internet hypertext reading-based on investigation and analysis of internet reading behavior. Library Work and Study, 10: 116-119.

[17] Barnes, S. (1994). Hypertext literacy. Interpersonal Computing and Technology, 4: 24-36.

[18] Sun, Z. (2011). A Comparative Study on EFL Learners' Reading Effects Between Hy-pertext and Printed Text in the Web-based Environment. Chongqing University.

[19] Wang, H. (2006). Hypertextualization of college English teaching from the perspec-tive of constructivism. Journal of Shandong Technology and Business University, 20 (5) :110-113.

[20] Li, C. (2010). Research on hypertext English autonomous learning and teaching strat-egies. Journal of Huaihua University, 29 (12):126-128.

[21] Zhang, X. (2013). A Comparative Study of English Majors' Reading Effects Between Hypertext and Traditional Printed Text in the Web-based Environment. Liaoning Normal University.

\section{Authors}

Hui Li is currently a graduate student in School of Languages and Literature, University of South China, Hengyang, China. Her research interests include second language acquisition and foreign language teaching. (873123889@qq.com)

Gengsheng Xiao is currently an associate professor in School of Languages and Literature, University of South China, Hengyang, China. His research interests include second language acquisition and corpus linguistics. (xgstudy@126.com).

Article submitted 14 May 2018. Resubmitted 09 June 2018. Final acceptance 19 June 2018. Fional version published as submitted by the authors. 